$$
\begin{gathered}
-6529 \\
p y
\end{gathered}
$$

\title{
Electrical Characterization of Glass, Teflon, and Tantalum Capacitors at High Temperatures
}

A.N. Hammoud

Sverdrup Technology, Inc.

Lewis Research Center Group

Brook Park, Ohio

and

E.D. Baumann, I.T. Myers, and E. Overton

National Aeronautics and Space Administration

Lewis Research Center

Cleveland, Ohio

Prepared for the

1991 Conference on Electrical Insulation and Dielectric Phenomena

sponsored by the Institute of Electrical and Electronics Engineers

Knoxville, Tennessee, October 20-24, 1991 



\title{
ELECTRICAL CHARACTERIZATION OF GLASS, TEFLON, AND TANTALUM CAPACITORS AT HIGH TEMPERATURES
}

\author{
A.N. Hammoud \\ Sverdrup Technology, Inc. \\ Lewis Research Center Group \\ Brook Park, Ohio 44142
}

\author{
E.D. Baumann, I.T. Myers, \\ and $\mathrm{E}$. Overton \\ National Aeronautics and Space Administration \\ Lewis Research Center \\ Cleveland, Ohio 441.35
}

\begin{abstract}
Dielectric materials and electrical components and devices employed in radiation fields and space environment are often exposed to elevated temperatures among other things. These systems must, therefore, withstand the high temperature exposure while still providing good electrical and other functional properties. In this work, experiments were carried out to evaluate glass, teflon, and tantalum capacitors for potential use in high temperature applications. The capacitors were characterized in terms of their capacitance and dielectric loss as a function of temperature up to $200^{\circ} \mathrm{C}$. At a given temperature, these properties were obtained in a frequency range of $50 \mathrm{~Hz}$ to $100 \mathrm{kHz}$. $\mathrm{DC}$ leakage current measurements were also performed in a temperature range from 20 to $200^{\circ} \mathrm{C}$. The results obtained are discussed and conclusions are made concerning the suitability of the capacitors investigated for high temperature applications.
\end{abstract}

\section{INTRODUCTION}

Dielectric and insulating materials are used extensively in many electrical systems and components such as high voltage capacitors, power cables, electronic switching and sensing devices, and energy storage and transport systems. These components and devices are ofien required to operate reliably in harsh environments where stresses of different kinds and intensities are encountered. High temperature constitutes one of these stresses which exists in space-based as well as terrestrial environments. Space exploration missions (Junar base), nuclear-powered space vehicles, integrated engine electronics, satellite power conditioning and SDI systems are examples of aerospace applications where high temperatures may be present.

In addition to being an environmental factor, heat is generated continuously by power processing and conditioning devices during operation. The generation of heat and its build-up are believed to greatly influence the performance of many power devices as they cause gradual degradation which eventually leads to catastrophic failure. This internally-developed thermal stress is becoming more severe as the currently emerging demand for aerospace technology places a great emphasis on increasing the energy densities and raising the power levels of space-based power systems and components. For instance, future plans for many space exploration missions call for tremendous increases in the power capability to a magnitude on the order of megawatts [1]. These requirements will certainly result in raising the operating temperature of the device/system concerned [2]. The development of high temperature insulating and dielectric materials, and power components and devices is therefore necessary to meet the challenges of advanced space power technology with objectives to reduce size and weight, increase packaging density, and improve performance and reliability. 
Glass, teflon, and tantalum capacitors were evaluated for potential use in high temperature applications. The capacitors were characterized in terms of their capacitance and dielectric loss as a function of temperature, up to $200{ }^{\circ} \mathrm{C}$, in a frequency range of $50 \mathrm{~Hz}$ to $100 \mathrm{kHz}$. The effect of temperature on the DC leakage current was also determined. In this paper, the experimental procedures and the results obtained are discussed.

\section{EXPERIMENTAL PROCEDURES}

The capacitors tested included glass (AVX Corp.), metallized-teflon (Component Research Co.), and solid tantalum (Mepco/Centralab). Table I lists some of the manufacturers" specifications [3-5].

Capacitance and dissipation factor of the capacitors were obtained as a function of temperature, up to $200^{\circ} \mathrm{C}$, using a Hotpack benchtop oven. At a given temperature, these properties were obtained in a frequency range of $50 \mathrm{~Hz}$ to $100 \mathrm{kHz}$ using a GenRad Model 1689 Digibridge. DC leakage current measurements were also performed in a temperature range from 25 to $200^{\circ} \mathrm{C}$ using a Keithley Model 237 Source-Measure Unit. In performing the leakage current experiments, the capacitor under test was allowed to charge by supplying the proper voltage through a $10 \mathrm{k} \Omega$ current-limiting resistor. DC voltages of $25 \mathrm{~V}$ and $50 \mathrm{~V}$ were applied in the case for glass and teflon, respectively, as these values correspond to the rated voltages with no deration required. The applied voltage for the tantalum capacitor, however, required deration with increase in temperature. The charging voltage applied was $125,100,75$, and $50 \mathrm{~V}$ at test temperature of 25 and $50,100,150$, and $200^{\circ} \mathrm{C}$, respectively. The leakage current was recorded 5 minutes after voltage application. Such a time was required for the current to reach stability. Each capacitor was then discharged completely before the next measurement was made.

\section{RESULTS AND DISCUSSIONS}

The change in capacitance with temperature at different frequencies for glass, metallized-teflon, and solid tantalum capacitors are shown in Figures 1-3, respectively. It can be clearly seen that while the teflon capacitor displayed excellent stability with temperature, the other capacitors exhibited changes, with opposite trends, in their capacitance with increased temperature. That is, while the glass capacitor exhibits initially a slight increase in capacitance which is then followed by a sharp decrease with temperature, the tantalum capacitor undergoes a steady increase in capacitance as the temperature is increased. Such an effect is seen to be more profound and is frequencydependent for the tantalum capacitor, as shown in Figure 3. It is important to note that in addition to being stable with temperature, the teflon capacitor showed no dependence on frequency as the data depicted in Figure 2 represents measurements taken from 50 $\mathrm{Hz}$ to $100 \mathrm{kHz}$. Similarly, the frequency had little effect on the capacitance value of the glass capacitor, as shown in Figure 1.

It is believed that changes in the capacitance of the glass and tantalum capacitors are indicative of variation in the dielectric constant of the respective material with temperature which can be attributed to dipole orientation that are intrinsically associated with the movement of ionic impurities between equilibrium energy positions in the 
material structure [6]. In addition, changes in the morphology, presence of fillers and additives, and thermally-induced molecular agitation might have contributed to changes in capacitance.

The dissipation factor of the teflon capacitor as a function of temperature and at different frequencies is shown in Figure 4. It can be seen that while this property remains constant with temperature at low frequencies, it exhibits an increase with increasing temperature at high frequencies. This can be attributed to dipole orientation, electronic polarization, and molecular relaxation that can follow the direction of the rapidly changing external field.

The changes in the dissipation factor of glass and tantalum capacitors with temperature and for different frequencies are shown in Figures 5 and 6, respectively. It is evident that the dissipation factor for both glass and tantalum capacitors seem to decrease with temperature except at low frequencies. At a frequency of $50 \mathrm{~Hz}$, for example, the dielectric loss of the glass capacitor initially decreases with an increase in temperature up to $100^{\circ} \mathrm{C}$, after which the loss starts to increase as the temperature is increased further. Similarly, the increase in the dielectric loss of the tantalum capacitor occurs at frequencies of $50 \mathrm{~Hz}$ and $1 \mathrm{kHz}$. Once again, the increase in the loss becomes significant as temperature exceeds $100^{\circ} \mathrm{C}$. The change in the loss behavior of both capacitors with temperature and frequency can be attributed to many factors and mechanisms such as the presence of impurities, ionic diffusion and migration [6], dipole orientation, and charge transpon phenomena. Thermal annealing occurring at high temperatures might have also led to changes in the dielectric loss property.

It is interesting to note that while the glass capacitor did not display the same stability with temperature as that of its teflon counterpart, its dielectric loss value at high temperatures is comparable to that of teflon. Amongst the three capacitors tested, the tantalum capacitor was the most lossy as its dissipation factor was at least an order of magnitude higher than the other two.

Figure 7 depicts the DC leakage currents of the capacitors as a function of temperature It can be seen that the leakage current for all capacitors in general increased with increasing temperature. The magnitude of these changes, however, are found to range from insignificant to very large, depending on the type of the dielectric. That is, while the leakage current of the teflon capacitor increased slightly and that of the tantalum capacitor exhibited a moderate increase, i.e. about an order of magnitude; the effect of temperature was more profound on the leakage current of the glass capacitor. At 200 ${ }^{\circ} \mathrm{C}$, for example, this increase amounted to a change of about 4 orders of magnitude from its room temperature value. While the slighvmoderate increase in teflon and tantalum capacitor leakage currents are thought to be attributed mainly to ohmic contact resistance and interfacial phenomena, the sharp increase in the leakage current of the glass capacitor with temperature is believed to be due to the presence of alkali impurity ions, primarily sodium [6].

It should be noted that although the leakage current of the glass capacitor exhibited a strong dependence on temperature, its magnitude was the lowest up to a temperature of about $100^{\circ} \mathrm{C}$, after which it started to exceed that of teflon. Also, at any given 
temperature, the tantalum capacitor had the highest leakage current value of the capacitors tested. This result seems to agree with that of dielectric loss measurements.

\section{CONCLUSION}

The results obtained in this work indicate that the dielectric properties depend greatly on temperature. Amongst the three capacitors tested, the teflon capacitor has shown superiority in terms of thermal stability. Further experimental studies are required to better and fully characterize these and other capacitors for potential use in high temperature environments.

\section{ACKNOWLEDGMENTS}

This work was supported by NASA Lewis Research Center, Contract \#NAS3-25266, Task Order \#5423-01, "High Temperature Dielectrics."

\section{REFERENCES}

[1] R. W. Bercaw, "Toward an Electrical Power Utility for Space Exploration," Proceedings of the European Space Power Conf., Madrid, Spain, Oct. 2-6, 1989.

[2] E. Sugimoto, "Applications of Polyimide Films to the Electrical and Electronic Industries in Japan, "IEEE Electrical Insulation Magazine, Vol. 5, No. 1, 1989.

[3] AVX Corporation, Glass Dielectric Capacitors, Brochure \#7892.5 MGDC-R.

[4] Component Research Co., High Reliability Film Capacitors, Catalog W.

[5] MEPCO/CENTRALAB-Philips Co., 88-89 Res/Cap. Data Book, Form 88-002.

[6] R. Bartnikas, "Dielectric Loss in Solids," Engineering Dielectrics, Vol. II, ASTM Publication-783, 1983.

Table 1. Capacitors specifications [3-5].

\begin{tabular}{|c|c|c|c|}
\hline Property & Glass & Teflon & Tantalum \\
\hline Capacitance $(\mu F)$ & 0.1 & 0.1 & 1.7 \\
\hline Capacitance Tolerance $(\%)$ & \pm 10 & 1 & \pm 10 \\
\hline Voltage (VDC) & 25 & 50 & $\begin{array}{l}125 \circ 85^{\circ} \mathrm{C} \\
850125{ }^{\circ} \mathrm{C}\end{array}$ \\
\hline Operating Temperature $\left({ }^{\circ} \mathrm{C}\right)$ & -75 to +200 & -65 to +200 & -55 to +200 \\
\hline Dissipation Factor (z) & $\begin{array}{l}3.0025{ }^{\circ} \mathrm{C} \\
4.0 @ 200^{\circ} \mathrm{C}\end{array}$ & $\begin{array}{l}0.05 \operatorname{Max} \\
025^{\circ} \mathrm{C}\end{array}$ & $\begin{array}{c}2.0 \mathrm{Max} \\
25^{\circ} \mathrm{C}, 120 \mathrm{~Hz}\end{array}$ \\
\hline
\end{tabular}




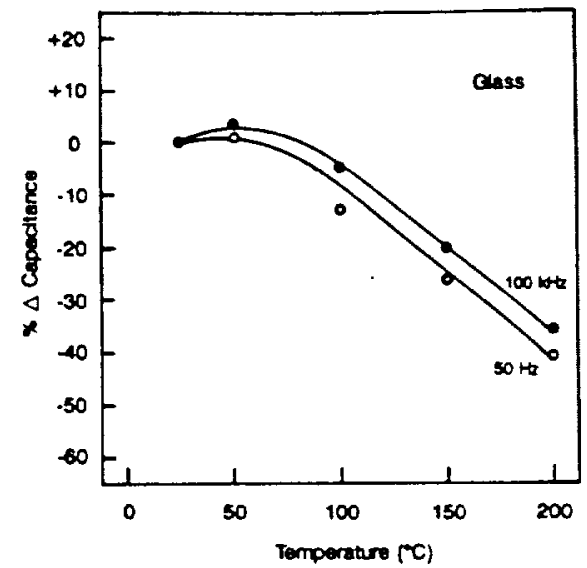

Figure 1. Change in capacitance of glass capacitor with temperature.

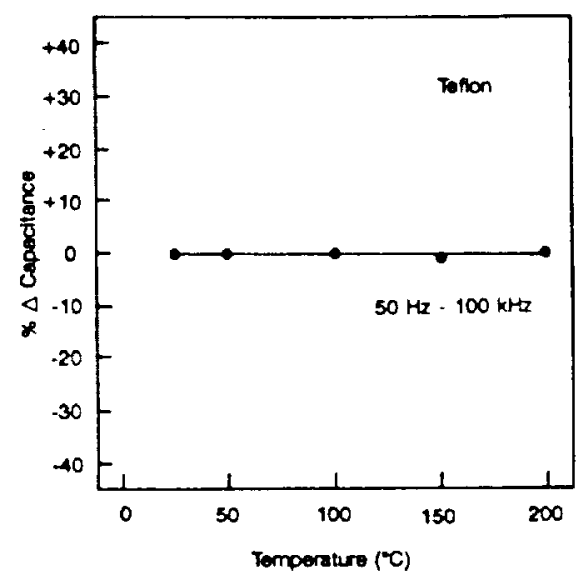

Figure 2. Change in capacitance of teflon capacitor with temperature.

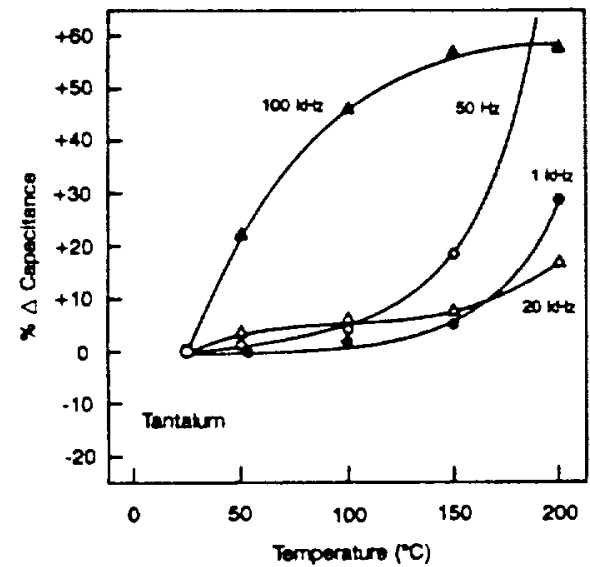

Figure 3. Change in capacitance of tantalum capacitor with temperature.

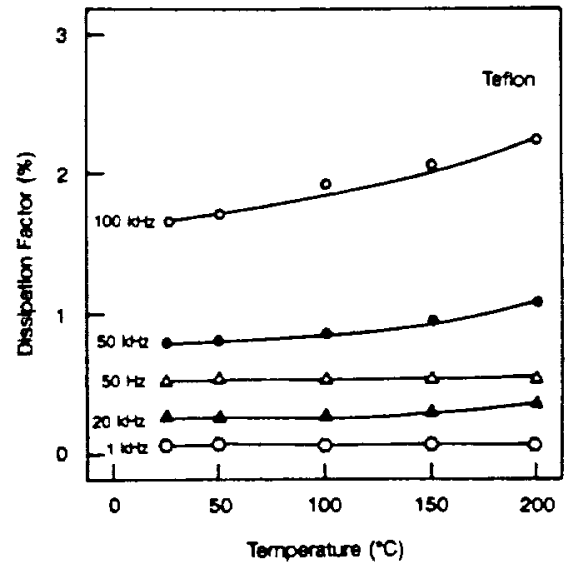

Figure 4. Dissipation factor of teflon capacitor as a function of temperature. 


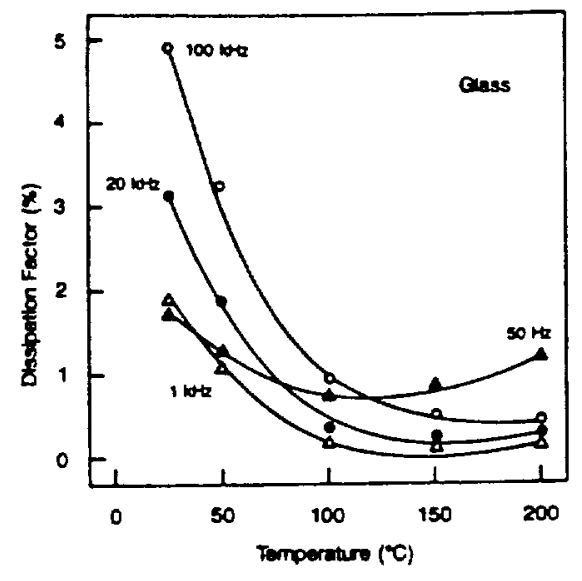

Figure 5. Dissipation factor of glass capacitor as a function of temperature.

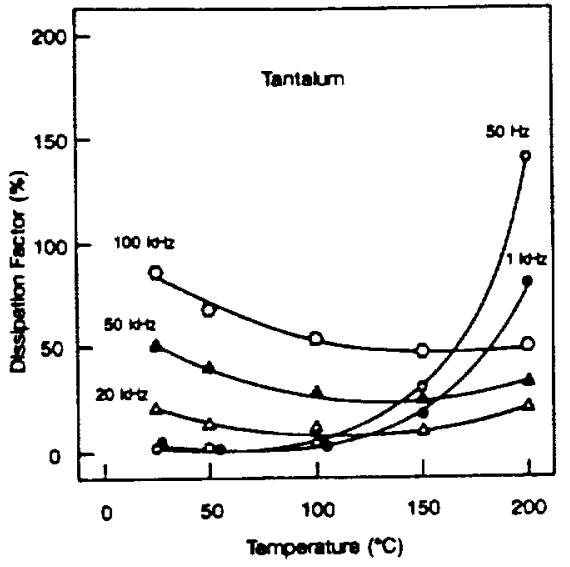

Figure 6. Dissipation factor of tantalum capacitor as a function of temperature.

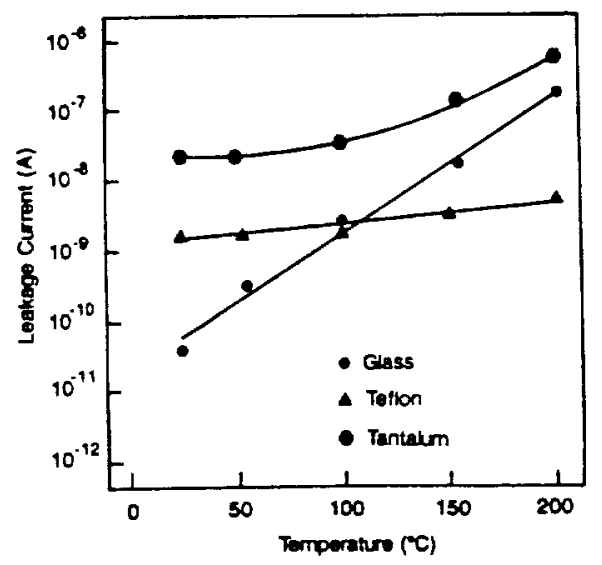

Figure 7. Comparison of leakage currents with temperature. 



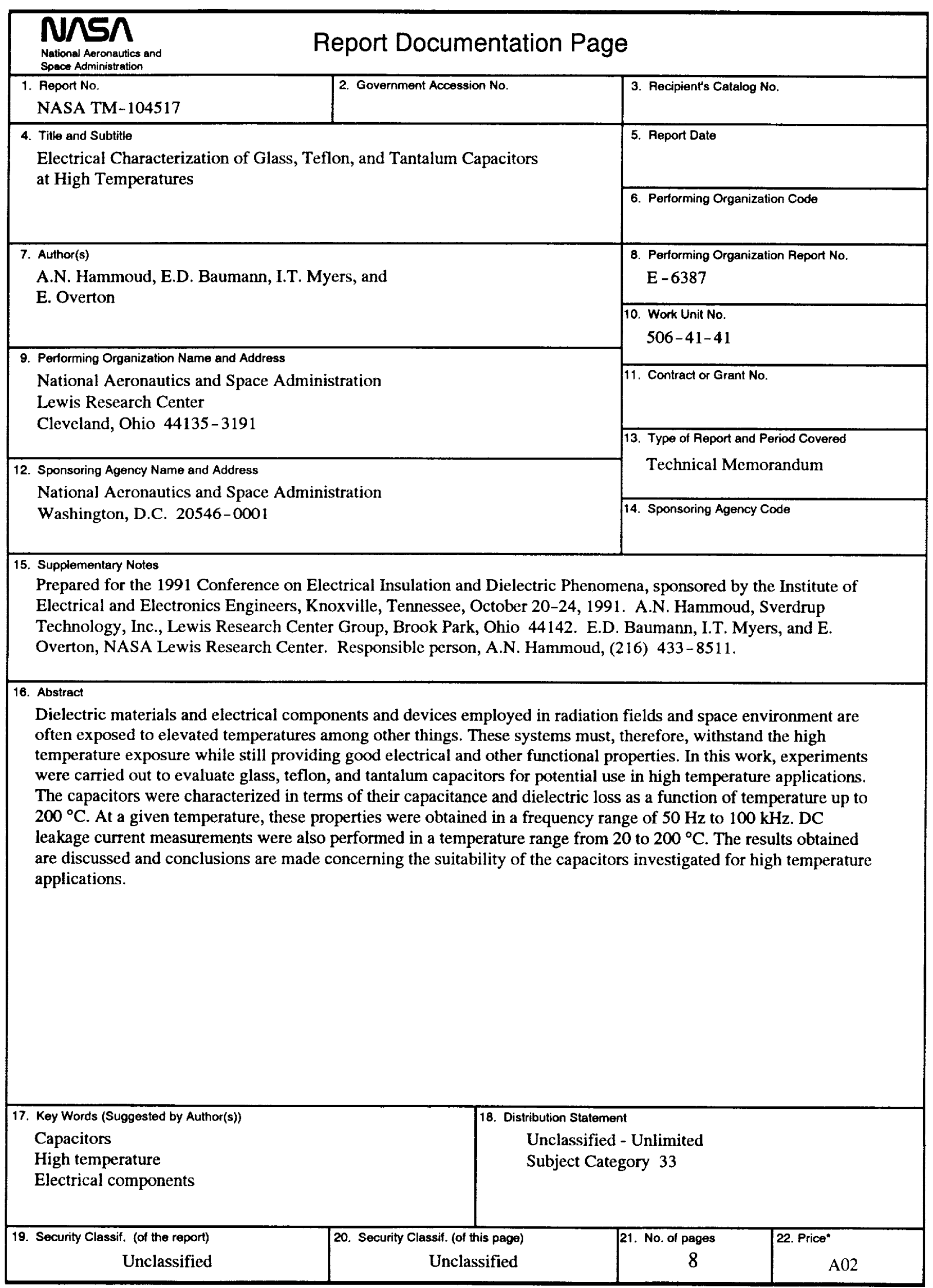

A.N. Hammoud, E.D. Baumann, I.T. Myers, and Performing Organization Report No. Work Unit No.

506-41-4

me and Address

11. Contract or Grant No

\section{Lewis}

and Address

Technical Memorandum 